\title{
The Study of Purine Utilization and Excretion in a Xanthinuric Man*
}

\author{
John H. Ayvazian $\dagger$ and Solomon Skupp \\ (From the Medical and Research Services, Veterans Administration Hospital, \\ New York, N. Y.)
}

The recent identification of a xanthinuric subject, the second such case to be described in the literature (1), afforded this laboratory the unique opportunity to study purine excretion and metabolism in a xanthine oxidase-deficient individual. Purine excretion was studied qualitatively and quantitatively, and the in vivo metabolism of purines was studied with the aid of $\mathrm{C}^{14}$-labeled guanine, adenine, and hypoxanthine.

Xanthine oxidase oxidizes hypoxanthine to xanthine and xanthine, in turn, to uric acid. It is the enzyme that activates the last step in normal purine catabolism in man. Xanthinuria, a rare metabolic defect, is associated with loss of xanthine oxidase activity in the liver and intestinal mucosa and the increased urinary excretion of xanthine and hypoxanthine, replacing uric acid. In the three xanthinuric subjects reported thus far in the English literature, the excretion of uric acid was minimal to absent while the subjects were on restricted purine intake, indicating that xanthine oxidase activates the principal pathway for the production of uric acid in man (1-3).

The purine excretion studies were done to determine if additional deviations from normal could be found other than those already described for the oxypurines. The radioisotope studies were done with the concept that the lack of xanthine oxidase, which blocks the direct conversion of hypoxanthine to xanthine, may facilitate and clarify the in vivo investigation of the intermediary metabolism of purines.

* Submitted for publication February 1, 1965 ; accepted April 2, 1965.

Work supported by U. S. Public Health Service research grants AI 02757-06 from the National Institute of Allergy and Infectious Diseases, Bethesda, Md., and the Veterans Administration.

† Address requests for reprints to Dr. John H. Ayvazian, Veterans Administration Hospital, First Ave. at East 24th St., New York 10, N. Y.

\section{Methods}

Uricase and xanthine oxidase, ${ }^{1}$ chromatographically pure reference purines (xanthine, hypoxanthine, adenine, and guanine), ${ }^{2}$ and the $C^{14}$-labeled purines ${ }^{3}$ were obtained commercially. Their specific activities were: guanine-8$\mathrm{C}^{14}, 11.9 \mathrm{mc}$ per mmole; adenine-8- $\mathrm{C}^{\mathbf{1 4}}$, $53.5 \mathrm{mc}$ per mmole; and hypoxanthine-8- $\mathrm{C}^{14}, 39.3 \mathrm{mc}$ per mmole.

Plasma and urinary uric acid were determined by an enzymatic spectrophotometric method (4). The uricase solution was diluted $1: 20$ to minimize the changes that occur in its optical density absorption at a wave length of $293 \mathrm{~m} \mu$ so that it would not significantly affect the assay of minute quantities of uric acid.

Xanthine and hypoxanthine were determined by the enzymatic method of Jørgensen and Poulsen (5), modified as reported previously (1). Creatinine was determined by Phillip's modification of the alkaline picrate method (6). A Beckman DU spectrophotometer was used for all the enzyme assays and spectral analysis.

Leukocytes were separated from whole blood by Lalezari's method (7). The nucleotide and nucleic acid fractions were extracted from the blood cells by Schneider's method (8). The nucleotides were assayed by the orcinol reaction (9), using adenylic acid 3 as the standard, and the DNA of the nucleic acid fraction was assayed by Burton's diphenylamine method (10) after acid hydrolysis of the nucleic acids.

Urines were collected in plastic containers under toluene in 24-hour samples (smaller, fractional samples were collected during the first day of each radioisotope study). The volume of each sample was measured and $5 \mathrm{ml}$ taken for the immediate (within 12 hours) determination of its uric acid, oxypurine, and creatinine concentrations as well as its radioactivity when applicable. The remainders of the samples were diluted to $4 \mathrm{~L}$ with water and, if selected for further study, were started through the process within 3 days of collection.

The subject received two diets during this study. The first diet was meat and methylpurine free and contained less than $10 \mathrm{mg}$ of purines in each 24-hour serving. It was ingested for 5 days, and during the last 2 days urine was collected for the identification and quantitation of trace urinary purines. The second diet was ingested dur-

1 Worthington Biochemical Corp., Freehold, N. J.

2 California Corporation for Biochemical Research, Los Angeles, Calif.

${ }^{\mathbf{3}}$ Schwarz Bioresearch, Inc., Orangeburg, N. Y. 
ing the radioisotope studies that extended over a 9-month period. This diet was methylpurine free and contained 60 $\mathrm{mg}$ of purines or less in one daily meat course. The details of this diet have been presented previously (11).

The methods used for the separation and identification of the urinary purines are based primarily on the methods developed and used by Weissmann, Bromberg, and Gutman $(12,13)$ and Wyngaarden, Blair, and Hilley (14). These methods involve the use of two stages of ion exchange chromatography utilizing Dowex $-50-\mathrm{H}^{+}$. The first stage utilized $8 \%$ cross-linked resin of 20 to 50 mesh and served to isolate and separate the urinary purines from urine. The second stage used a $12 \%$ cross-linked resin of 200 to 400 mesh and served to isolate and separate the individual purines by gradient elution and fractional collection. Modifications of the method were required because of the relative lack of uric acid and the high concentrations of xanthine and hypoxanthine. The diluted urine was filtered through a Buchner funnel with Whatman 1 filter paper to eliminate the urinary sediment. The filtrate was acidified with concentrated hydrochloric acid to $\mathrm{pH} 2$ and placed on the first ion exchange column taking 4 hours to completely charge the column. This column was $5 \mathrm{~cm}$ in diameter and filled with resin to a height of $40 \mathrm{~cm}$. The column was washed and charged and eluted as previously described except that $4 \mathrm{~L}$ of $1 \mathrm{M}$ ammonium hydroxide was needed to completely elute the large amount of oxypurines. The preparation of the first eluate for the second stage of the chromatographic separation involved concentration by evaporation of the ammonium hydroxide eluate, precipitation of the purines with silver nitrate, and washing and dissolving in hydrochloric acid. This was done as originally described, but a modification was necessitated by the precipitation of a large proportion of the oxypurines during the partial evaporation of the eluate. This precipitate was quantitatively removed by serial transfer and centrifugation. It was washed three times with water and the wash water added to the original supernatant. The precipitate was dried in a desiccator, in vacuum, over anhydrous calcium sulfate (Drierite). It was determined by enzymatic analysis, differential spectrophotometry, and paper chromatography that this precipitate contained only xanthine and a relatively small amount of hypoxanthine. Accordingly, the precipitate was quantitated by converting a dissolved sample to uric acid with xanthine oxidase, and the molar equivalents of uric acid were determined by the uricase assay. The relative proportion of xanthine to hypoxanthine was determined by using the differential spectrophotometric method of Jørgensen (15), which gave accurate results at the relative concentrations of xanthine and hypoxanthine present in these relatively pure precipitates. The values obtained for each sample were added to those of xanthine and hypoxanthine determined after gradient elution chromatography of the remaining purines of the same sample.

The column used for gradient elution was $2.5 \mathrm{~cm}$ in diameter and was filled with resin to a height of $31 \mathrm{~cm}$. It was charged with the solution of purines isolated by silver salt precipitation and redissolved in hydrochloric acid. This solution contained all of the trace purines in addition to the xanthine and hypoxanthine that did not precipitate during the initial concentration by evaporation of the first eluate. Gradient elution was started with 0.15 $\mathrm{N}$ hydrochloric acid and gradually increased to $4.0 \mathrm{~N}$ hydrochloric acid using a volume of $7 \mathrm{~L}$ of eluate. This was collected in 700 tubes in $10-\mathrm{ml}$ samples over a 60 -hour period. The tubes containing the individual purines, which were well defined, were pooled, evaporated to dryness, and redissolved in a known volume of water using $10 \mathrm{ml}$. Samples were then re-evaporated to dryness and redissolved in the various appropriate buffers and solutions for differential spectrophotometry of $\mathrm{pH} 2.1$ and 9.0, paper chromatography, and enzymatic analysis.

The paper chromatographic methods used by Weissmann and his associates $(12,13)$ were also used in this study. However, although both systems (butanol:ammonia and butanol: formic acid) were used, the purines were chromatographed in one dimension on two different papers. A two dimensional system was not needed as we used the individual purines isolated by gradient elution rather than the purine mixtures. In addition, the relatively high concentration of xanthine made chromatography of the pooled purines impractical as the purines present in trace amounts could not be visualized at the dilutions used.

The $\mathrm{C}^{14}$-labeled purines were administered intravenously in $10 \mathrm{ml}$ of sterile aqueous $\frac{1}{6} \mathrm{M}$ lactate. The subject was first given $25 \mu \mathrm{c}$ of guanine and his urine collected thereafter. During the first 24 hours his urine was collected in three samples of 4,8 , and 12 hours duration, respectively. After this, 24-hour samples were collected uninterrupted for 2 weeks and then once or twice a week. These collections continued until the radioactivity in the urine returned to background levels. This collection procedure was followed after each injection of labeled purine. Six weeks after the injection of guanine the subject was given $100 \mu \mathrm{c}$ of adenine-8-C $C^{14}$. It took approximately 6 months for his urine radioactivity to return to background levels after which he was given $25 \mu \mathrm{c}$ of hypoxanthine-8- $C^{14}$, and the same procedures were followed. The urine samples selected for study were processed as described earlier. Ion exchange and paper chromatographic isolation of the purines were done to obtain specific activities as disintegrations per minute per micromole for each individual purine. In counting the purines it was found that accurate specific activities could be obtained for xanthine, hypoxanthine, 7-methylguanine, and adenine by using tubes containing high concentrations of the purines obtained directly from the fraction collector. These tubes were evaporated to dryness and reconstituted in 5 $\mathrm{ml}$ of $0.16 \mathrm{M}$ Tris buffer; this buffer had the same quenching as an equal volume of water. At least three different tubes of varying concentration were counted for each of these four purines, and each set consistently gave closely similar results, which were averaged. The tubes containing 1-methylxanthine, $N^{2}$-methylguanine, 1-methylguanine, and guanine were pooled individually, evaporated to dryness, and redissolved in a smaller volume of $1 \mathrm{M}$ ammonium hydroxide. Their specific activities were ob- 
tained after recovery of the purine by paper chromatography that removed contaminating adjacent purines (Figure 1) and fluorescent material.

Urine and purine samples were counted using a liquid scintillation counter (Packard Tri-Carb model 314 EX). A standard dioxane solvent system was used and an efficiency of approximately $60 \%$ obtained. Samples were counted to give $95 \%$ confidence limits or more. Quenching was determined by the use of a solution of adenine8-C ${ }^{14}$ as the internal standard.

\section{Results}

Isolation and identification of urinary purines. The elution pattern obtained is shown in Figure 1. This pattern is representative of 7 gradient elution studies, all of which produced the same elution sequence with only minimal variations in the tube numbers. Fifteen peaks were obtained, 13 constant and 2 inconstant. Of these 15,8 peaks, constantly present, were positively identified as purines. These were, in order of elution, xanthine, hypoxanthine, 1-methylxanthine, guanine, $N^{2}$-methylguanine, 1-methylguanine, 7-methylguanine, and adenine. Excellent separation was obtained in all the peaks. The remaining peaks shown have not as yet been identified, and at present the various pools of these unknown peaks are being consolidated for further studies.

Identification of the purines is based on four criteria : 1) movement, or sequence of elution, on an ion exchange column, 2) ultraviolet (UV) spectra obtained at $\mathrm{pH} 2.1$ and $9.0,3) \mathrm{R}_{\mathrm{f}}$ values obtained by two paper chromatographic systems, and 4) oxidation by xanthine oxidase.

The elution sequence, UV spectra, and $R_{f}$ values obtained from the purines isolated from the subject's urine corresponded closely with those of the appropriate purine standard and with the appropriate data obtained from published observations of Weissmann and his associates (12). The oxidation of xanthine and hypoxanthine to uric acid was confirmed by the shift in their UV absorption spectra to that of uric acid and the subsequent conversion of the uric acid to allantoin by uricase. The oxidation of 1-methylxanthine to 1-methyluric acid was demonstrated by the shift in the UV absorption spectra to that of 1-methyluric acid, which is identical to that of uric acid (16) but does not change further with the addition of uricase. The oxidation of adenine to 2, 8dihydroxyadenine was confirmed by the slow reaction rate and the characteristic shift of the UV absorption spectrum (17).

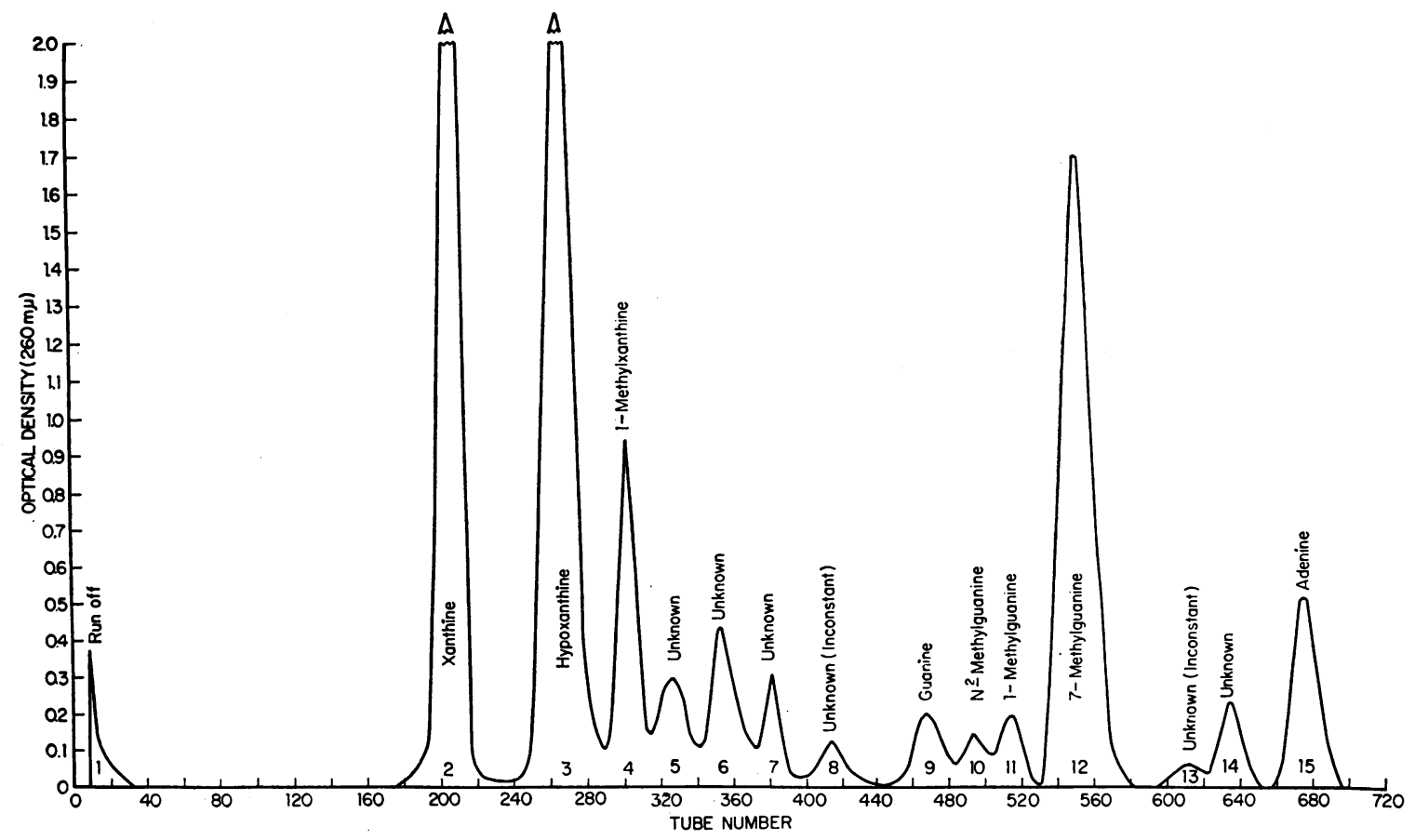

Fig. 1. Elution Pattern of URINARY PURINes. 
TABLE I

Urinary excretion of purines

\begin{tabular}{|c|c|c|c|c|c|c|c|}
\hline \multirow[t]{2}{*}{ Substance } & \multicolumn{2}{|c|}{ Special diet } & \multicolumn{5}{|c|}{ Standard low purine diet } \\
\hline & \multicolumn{2}{|c|}{$m g / d a y$} & \multicolumn{5}{|c|}{$m g / d a y$} \\
\hline Uric acid* & 12 & 15 & 0 & 9 & 5 & 16 & 0 \\
\hline Creatinine & 1,114 & 1,236 & 1,444 & 1,393 & 1,549 & 1,409 & 1,283 \\
\hline Oxypurinet & 612 & 696 & 475 & 504 & 527 & 541 & 497 \\
\hline Xanthine & 350 & 431 & 344 & 371 & 372 & 388 & 342 \\
\hline Hypoxanthine & 114 & 146 & 59.7 & 74.2 & 66.4 & 89.3 & 58.0 \\
\hline 1-Methylxanthine & 0.3 & 1.0 & 1.5 & 3.6 & 4.3 & 3.8 & 3.3 \\
\hline Guanine & 0.4 & 1.6 & 1.0 & 2.1 & 2.1 & 2.7 & 2.1 \\
\hline$N^{2}$-Methylguanine & 0.6 & 0.9 & 0.8 & 0.9 & 1.2 & 1.3 & 1.1 \\
\hline 1-Methylguanine & 0.7 & 1.0 & 0.6 & 0.8 & 0.9 & 1.8 & 0.8 \\
\hline 7-Methylguanine & 9.2 & 8.7 & 10.6 & 11.3 & 12.7 & 15.2 & 11.3 \\
\hline Adenine & 1.4 & 1.1 & 1.5 & 2.6 & 2.2 & 3.0 & 2.1 \\
\hline
\end{tabular}

* Zero implies no uric acid detected by enzymatic analysis.

$\dagger$ Oxypurines found in original urine by enzymatic analysis given in uric acid equivalents and corrected for actual uric acid found in specimen.

While the subject was on a regular diet containing methylpurines, 7-methylxanthine and 1,7methylxanthine were isolated and identified from his urine. These were not present in his urine while he was ingesting a methylpurine-free diet. However, 1-methylxanthine was consistently identified in all his urine samples.

Quantitation of urinary purines. The precipitates of oxypurines obtained during the concentration of the first eluate of each of the seven 24-hour urine samples weighed from 215 to $480 \mathrm{mg}$. Analysis of these precipitates by the combined enzymatic and spectrophotometric method (15) found an oxypurine content ranging from 0.98 to 2.75 mmoles with the xanthine content making up 91 to $99 \%$ of the total. These amounts were added to the values determined for xanthine and hypoxanthine, which remained in solution in the first eluate. The quantitative determination of the eight known purines separated by gradient elution chromatography was done spectrophotometrically, utilizing the optical density obtained at the absorption maximum at $\mathrm{pH} 2.1$ for each purine and the extinction coefficients for each purine as detailed by Weissmann and his associates (13).

The values obtained in the analysis of seven different 24-hour urine samples are listed in Table I. Five of these urines were collected while the subject was ingesting the standard low purine diet ( $60 \mathrm{mg}$ of purine per day), and the purine and creatinine contents of these specimens are in relatively close agreement. The mean values calculated for the purines of these five specimens are (in mg per 24 hours) : xanthine, 363 ; hypoxanthine, $69.5 ; 1$-methylxanthine, 3.3 ; guanine, 2.0 : $N^{2}$-methylguanine, $1.1 ; 1$-methylguanine, $1.0 ; 7$ methylguanine, 12.2; and adenine, 2.3.

The first two columns of Table I contain the data obtained from urine collected while the subject was ingesting a special low purine diet (less than $10 \mathrm{mg}$ per day). The oxypurine contents of these two samples were somewhat higher and the trace purines lower than the other five samples.

Table II presents data relative to the oxypurines

TABLE II

Excretion and recovery of oxypurines in urine

\begin{tabular}{|c|c|c|c|c|c|c|c|}
\hline \multirow[b]{2}{*}{$\begin{array}{l}\text { Oxypurine content by } \\
\text { enzymatic analysis* } \\
\text { Xanthine* } \\
\text { Hypoxanthine* } \\
\text { Per cent recovery } \\
\text { Per cent xanthine }\end{array}$} & \multicolumn{2}{|c|}{ Special diet } & \multicolumn{5}{|c|}{ Standard low purine diet } \\
\hline & $\begin{array}{c}3.64 \\
2.31 \\
0.84 \\
87 \\
73\end{array}$ & $\begin{array}{c}4.14 \\
2.84 \\
1.08 \\
95 \\
72\end{array}$ & $\begin{array}{c}2.83 \\
2.26 \\
0.44 \\
95 \\
84\end{array}$ & $\begin{array}{c}3.00 \\
2.44 \\
0.55 \\
99 \\
82\end{array}$ & $\begin{array}{c}3.14 \\
2.45 \\
0.49 \\
94 \\
83\end{array}$ & $\begin{array}{c}3.22 \\
2.55 \\
0.66 \\
99 \\
79\end{array}$ & $\begin{array}{c}2.96 \\
2.25 \\
0.43 \\
91 \\
84\end{array}$ \\
\hline
\end{tabular}

* Values expressed as millimoles per day. 


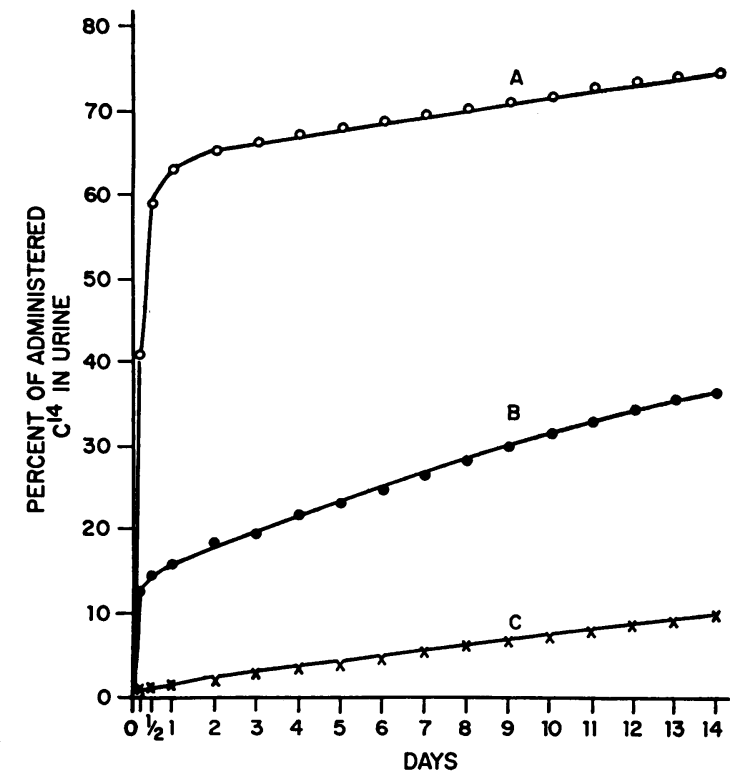

Fig. 2. Cumulative excretion of $C^{14}$ in URine. Plotted as per cent of administered dose after intravenous administration of $25 \mu \mathrm{c}$ of guanine-8-C ${ }^{14}$ (A), $25 \mu \mathrm{c}$ of hypoxanthine-8- $C^{14}(B)$, and $100 \mu \mathrm{c}$ of adenine- $8-C^{14}(C)$.

obtained from the seven specimens and listed in millimoles. Recovery was calculated by combining the values for xanthine and hypoxanthine, determined spectrophotometrically, and comparing that value to the nonuric acid oxypurine content of the raw urine originally determined by enzymatic analysis. Recovery varied from 87 to $99 \%$. Xanthine was excreted in larger amounts than hypoxanthine in all of these urines. The per cent xanthine, calculated on a millimole basis, ranged from 72 to $84 \%$ of the total recovered oxypurine.

Results of studies with radioactive purines. The total $\mathrm{C}^{14}$ activity was determined for each urinary sample collected in the 2 -week periods after the administration of the labeled purines. After fractional analysis of the individual urines it was found that 80 to $92 \%$ of the total counts observed in the urine could be accounted for by the radioactivity of the eight identified purines. The total disintegrations per minute for the urines were calculated, and corrected for quenching and efficiency. The cumulative excretion curves, plotted as per cent of the administered dose relative to time, are shown in Figure 2. The excretion curves, plotted from the data obtained after administration of guanine-8- $\mathrm{C}^{14}$ and hypoxanthine-8- $\mathrm{C}^{14}$, show an initial rapid phase of excretion within the first 24 hours that blends into a slower phase of excretion that continues throughout the remainder of the 14day period. This rapid initial phase is not apparent after the injection of adenine-8- $\mathrm{C}^{14}$.

After the administration of $25 \mu \mathrm{c}$ of guanine$8-\mathrm{C}^{14}, 63 \%$ of the injected $\mathrm{C}^{14}$ was excreted in the first 24 hours and $74 \%$ within the first 2 weeks. After $25 \mu \mathrm{c}$ of hypoxanthine-8-C $\mathrm{C}^{14}, 16 \%$ of the injected $\mathrm{C}^{14}$ was eliminated in the first 24 hours and $36 \%$ during the first 2 weeks. Only $1 \%$ of the injected $\mathrm{C}^{14}$ was excreted in the first 24 hours following the administration of $100 \mu \mathrm{c}$ of adenine$8-C^{14}$. This increased to $9 \%$ by the completion of the 2 -week period. The slopes of the excretion curves calculated for a 10-day period from day 3 to 13 after injection are $0.6,0.7$, and $1.6 \%$ per day for the adenine, guanine, and hypoxanthine studies, respectively.

The specific activities determined for the purines isolated from the first 4-hour sample collected after the administration of $25 \mu \mathrm{c}$ of labeled guanine showed the expected high specific activity of guanine $(300,000 \mathrm{dpm}$ per $\mu$ mole $)$, which fell rapidly thereafter, and xanthine $(36,000 \mathrm{dpm}$ per $\mu$ mole $)$, but significant labeling was also observed in 1-methylxanthine $(45,000 \mathrm{dpm}$ per $\mu$ mole $), 7$ methylguanine $(1,900 \mathrm{dpm}$ per $\mu$ mole $)$, hypoxanthine $(3,100 \mathrm{dpm}$ per $\mu$ mole $)$, and adenine (900 dpm per $\mu$ mole). By the second day labeling was also apparent in $N^{2}$-methylguanine and 1-methylguanine. The specific activities obtained for the various purines throughout the study are shown in Figure 3. For graphic simplicity the specific activities of only four purines have been charted in all three studies, xanthine, hypoxanthine, 7-methylguanine, and adenine. Except during the first 24 hours the specific activities of guanine, 7-methylguanine, $N^{2}$-methylguanine, and 1-methylguanine were almost identical and changed in parallel in this and the other two studies. Despite a rapid decay rate the specific activities of xanthine and hypoxanthine could be determined accurately as late as day 23. The decay rate for hypoxanthine and adenine was relatively slower than that for xanthine, guanine, and the guanine derivatives. This is shown in Figures 4 and 5, which plot the ratio of the specific activities of xanthine to hypoxanthine and 7-methylguanine to adenine over time. The significance of these data will be discussed. 


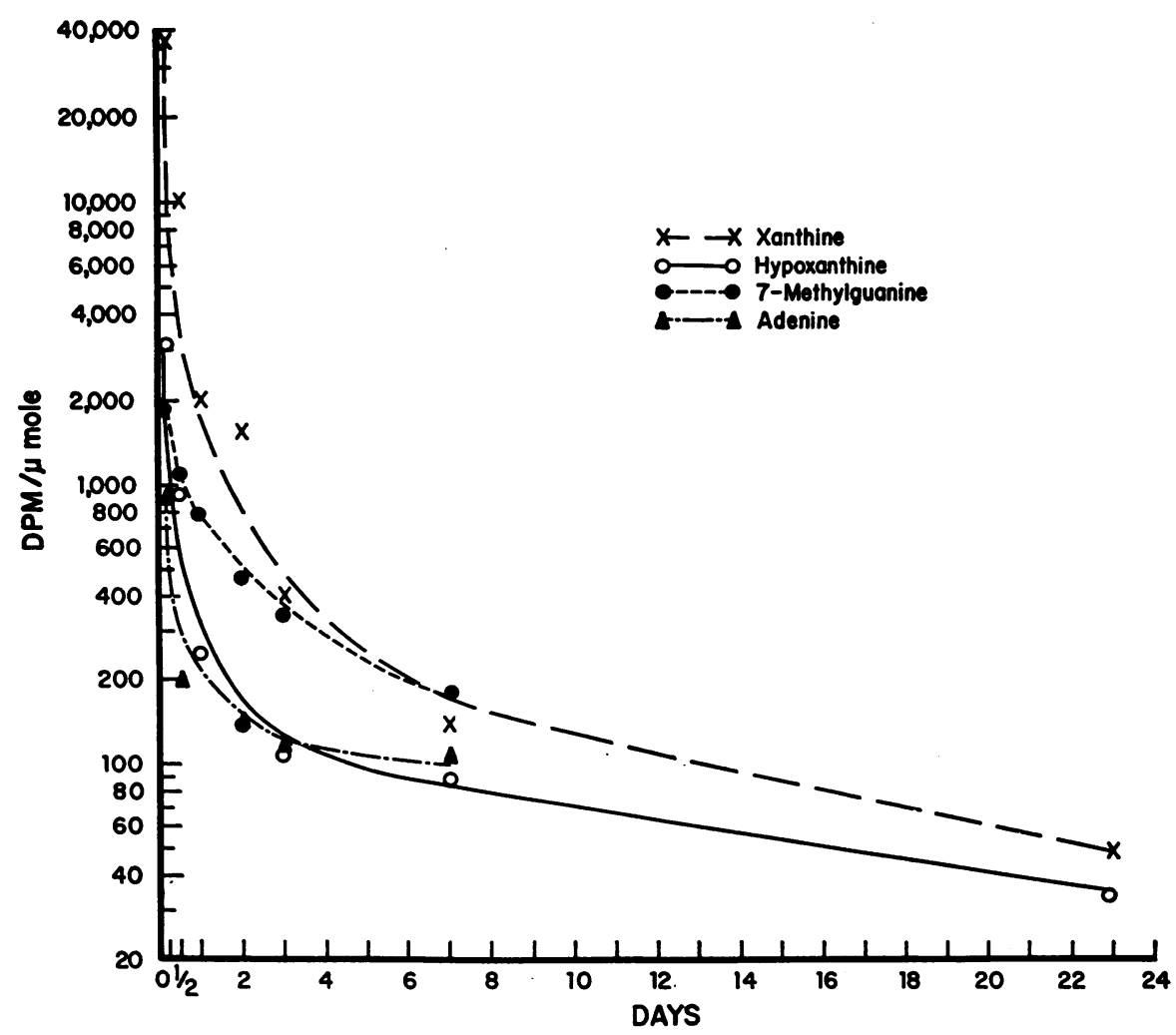

Fig. 3. Pattern of labeling of URINARy PURINes AFter intravenous administration OF $25 \mu \mathrm{C}$ OF GUANINE-8-C $\mathrm{C}^{14}$.

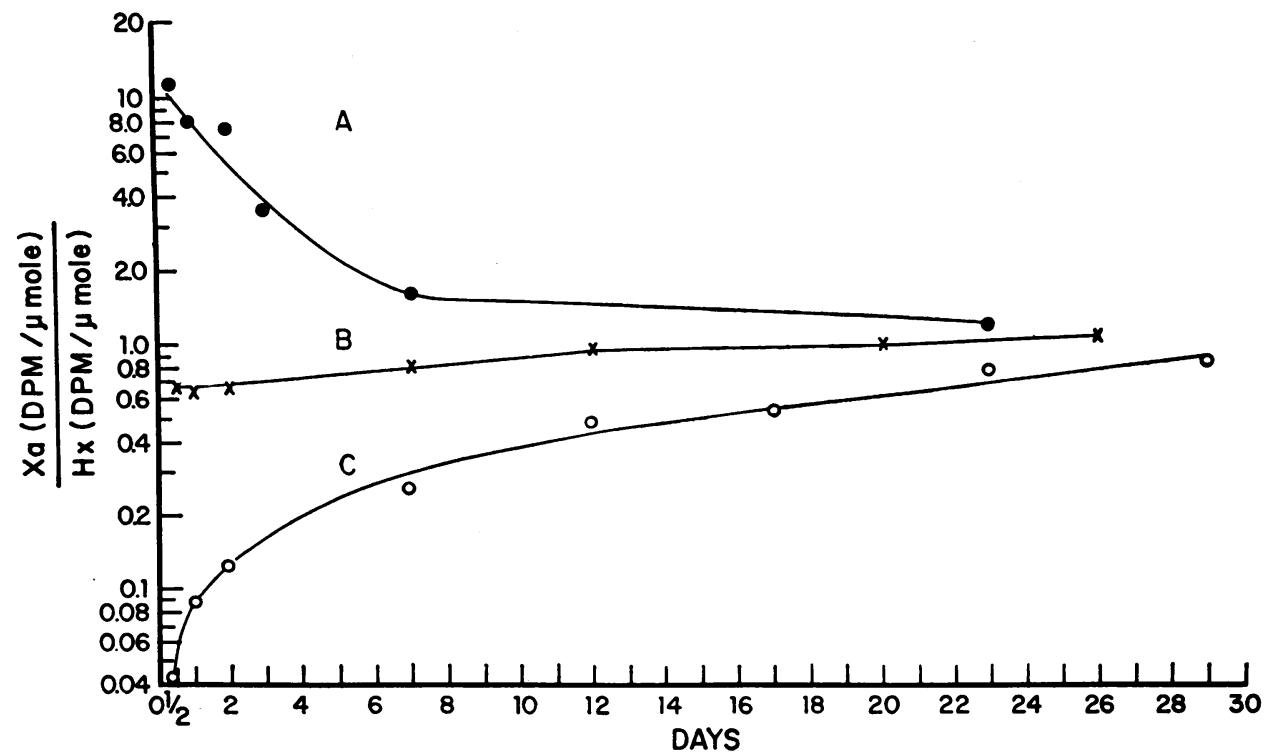

Fig. 4. Semilogarithmic plot of RAtios of SPECIFIC ACtivities of Xanthine to hypoXANthine. Data obtained from the guanine-8- $C^{14}$ study (A), hypoxanthine-8- $C^{14}$ study (B), and adenine-8- $C^{14}$ study (C). 


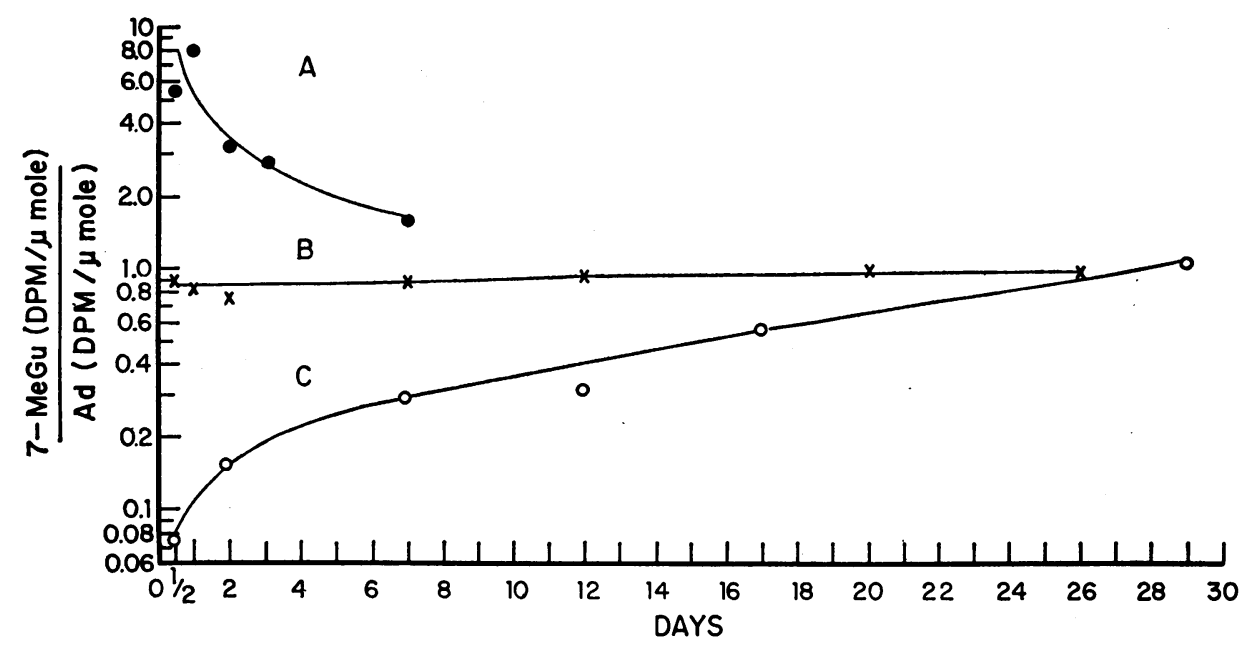

Fig. 5. Semilogarith mic plot of Ratios of SPECIFIC ACtivities of 7-Methylguanine to ADENINE. Data obtained from the guanine-8-C $C^{14}$ study (A), hypoxanthine-8-C ${ }^{14}$ study (B), and adenine-8- $\mathrm{C}^{14}$ study $(\mathrm{C})$.

After the administration of $100 \mu \mathrm{c}$ of adenine8- $\mathrm{C}^{14}$ all of the identified purines of the first sample of urine collected showed labeling. The expected difference between hypoxanthine and xan- thine was observed with specific activities of 800 $\mathrm{dpm}$ per $\mu$ mole and $30 \mathrm{dpm}$ per $\mu$ mole, respectively. The highest specific activity observed was that of adenine with $6,000 \mathrm{dpm}$ per $\mu$ mole as com-

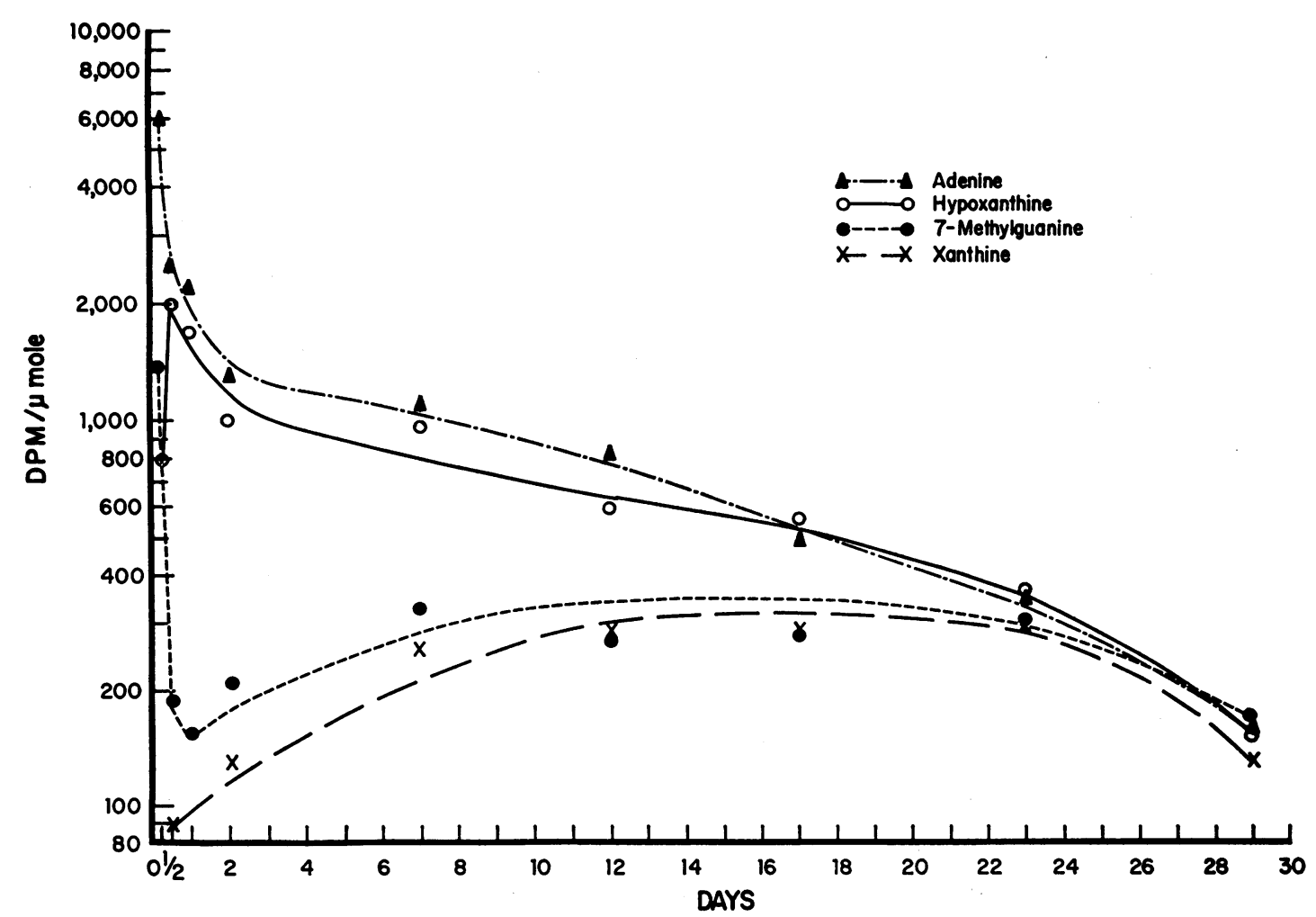

Fig. 6. Pattern of Labeling OF URINARY PURINES AFTER INTRAVENoUS ADMinistration of $100 \mu \mathrm{C}$ of ADENINE-8-C ${ }^{14}$. 


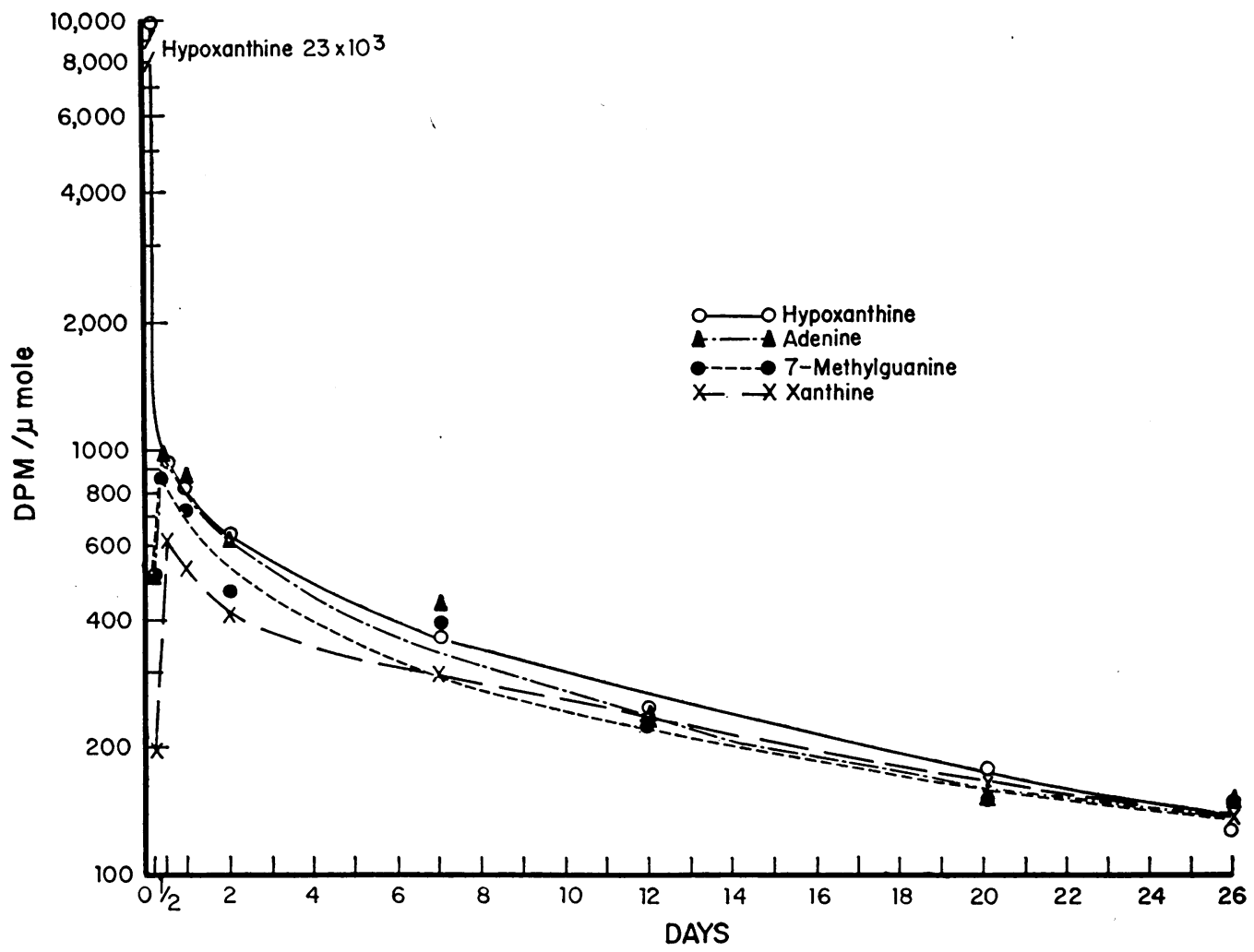

Fig. 7. Pattern of labeling of URinary PURines AFter intravenous administration of $25 \mu \mathrm{C}$ of hyPOXANTHINE-8-C ${ }^{14}$.

pared to $950 \mathrm{dpm}$ per $\mu$ mole for guanine. In addition to the determinations of the first three samples, the specific activities obtained from the purines collected on days $2,7,12,17,23$, and 29 are plotted in Figure 6. The specific activity of hypoxanthine peaked during the second sample (4 to 12 hours) and declined slowly thereafter, whereas the specific activity of xanthine increased slowly and was maximal from days 12 to 23 . The initially high specific activity of guanine and the substituted guanines fell after the first sample and paralleled that of xanthine thereafter. The decay of the specific activities of hypoxanthine and adenine was relatively more rapid than that of xanthine and the guanine derivatives. This is apparent in Figures 4 and 5 in which the ratios of the specific activities of xanthine to hypoxanthine and 7-methylguanine to adenine are plotted over time.

The specific activities determined for the purines isolated from the first urine sample obtained after the hypoxanthine-8- $\mathrm{C}^{\mathbf{1 4}}$ study showed the expected disproportion between hypoxanthine $(23,000 \mathrm{dpm}$ per $\mu$ mole) and xanthine (200 dpm per $\mu$ mole), but the other purines had essentially similar specific activities that decayed in parallel. This is shown in Figure 7. The differences between xanthine and hypoxanthine quickly disappeared with the rapid decline of the hypoxanthine radioactivity, and their specific activities were equal by day 12 after injection. Thereafter all of the purines showed parallel decreases in specific activity, and the ratio of specific activities for xanthine to hypoxanthine and 7-methylguanine to adenine remained near 1, as shown in Figures 4 and 5.

Fifty-ml samples of whole blood were obtained from the subject on days $5,13,21$, and 30 after the injection of hypoxanthine-8- $\mathrm{C}^{14}$. The erythrocytes and leukocytes were separated and the specific activities determined for the erythrocyte nucleotides and the leukocyte nucleic acids. The data are shown in Figure 8. Labeling was found in both fractions. The specific activity of the nucleotides decreased from the initially high value of $1,000 \mathrm{dpm}$ per $\mathrm{mg}$ of mononucleotide, whereas 


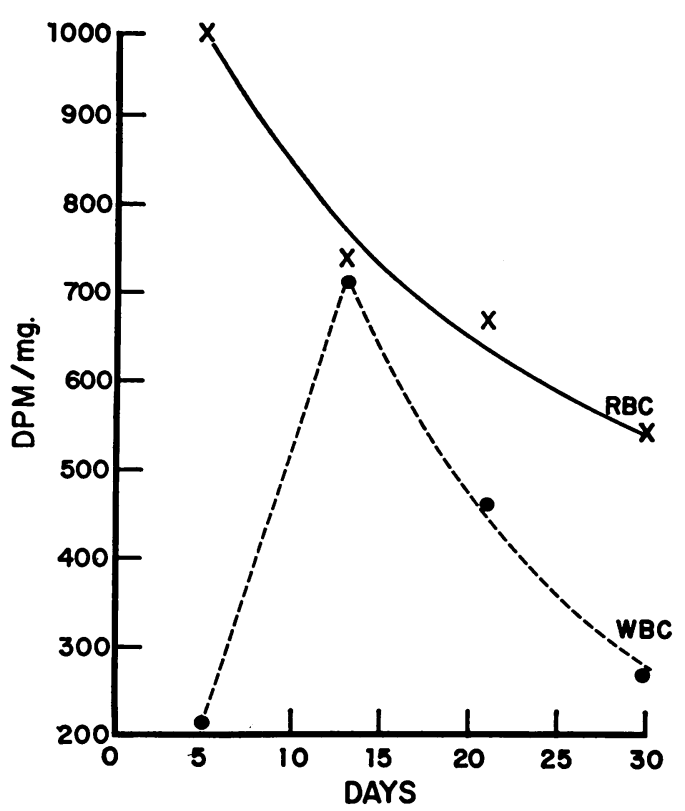

FIG. 8. LABELING OF ERYTHROCYTE NUCLEOTIDES AND LEUKOCYTE NUCLEIC ACIDS AFTER HYPOXANTHINE-8-C ${ }^{14}$ STUDY.

the nucleic acids demonstrated a peak in activity at day 13.

\section{Discussion}

The studies of this xanthinuric subject's excretion of urinary purines found the expected marked decrease in uric acid associated with a compensatory increase in excretion of its precursor oxypurines, xanthine and hypoxanthine. The relatively greater excretion of xanthine by this subject, compared to hypoxanthine, has been noted in other xanthinuric patients $(3,18)$. The six remaining identified purines were present in amounts comparable to those observed by Weissmann and associates (13) in their study of normal subjects.

The uric acid found in the reported specimens varied from undetectable amounts (using 0.1 dilution of urine with an assay method sensitive to 0.1 $\mathrm{mg}$ per $100 \mathrm{ml}$ ) to $16 \mathrm{mg}$ per 24 hours. The origin of this uric acid is not known, but previous observations $(1,2,18)$ suggest a dietary origin, in part. Another probable mechanism is the conversion of endogenously produced hypoxanthine and xanthine by intestinal bacteria. Endogenous pathways for the production of uric acid, in the absence of xanthine oxidase, could exist as suggested by Engelman and associates (3), but, if they do, they are probably of trivial importance as they state.
When the subject was given the strict low purine diet, his oxypurine excretion steadily increased over the 5-day period and was maximal on the last 2 days of this diet. The increase was most apparent in the hypoxanthine fraction. This observation requires further study and documentation, but it is interesting to speculate if an acceleration of the de novo synthesis of inosinic acid (IMP) and the "shunt pathway" bypassing nucleic acids was involved (19).

In our studies we consistently found 1-methylxanthine despite a methylpurine-free diet, unlike the observations of Weissmann and associates $(12,13)$, indicating that this compound is of endogenous origin. This was confirmed by our detection of $\mathrm{C}^{\mathbf{1 4}}$-labeled 1-methylxanthine after the administration of each of the three labeled purine bases. The presence of endogenously formed 1-methylxanthine in this individual may be directly related to his enzyme defect and large xanthine pool.

Studies on the unidentified substances are continuing and will be reported in a subsequent publication.

Discussion of studies with radioactive purines. The excretion of $\mathrm{C}^{14}$-labeled purines after the injection of each of the three labeled bases reflects their degree of utilization as well as their turnover after incorporation. All of these bases can be readily utilized by microbiological systems $(20,21)$. The utilization of guanine and hypoxanthine by mammalian systems is less clearly demonstrated. Mammalian cells are capable of incorporating guanine and hypoxanthine in vitro (22-24) in the absence of xanthine oxidase, but the evidence for incorporation in vivo by whole organisms is much less definite $(25,26)$, especially when compared to the obvious incorporation of adenine (25). However, the data of Wyngaarden, Seegmiller, Laster, and Blair suggest that man is capable of in vivo incorporation and conversion of hypoxanthine (25).

Our data show that all three of these bases are incorporated in varying degree by this xanthine oxidase-deficient subject, with adenine being incorporated most avidly and guanine the least. In a similar study utilizing smaller doses of adenine-8- $\mathrm{C}^{14}$ and hypoxanthine- $8-\mathrm{C}^{14}$, Wyngaarden and his associates (25) found that nonxanthine oxidase deficient individuals excreted a 
moderately higher percentage, relative to dose, of $\mathrm{C}^{14}$-labeled purines than did our subject. Although conclusions cannot be made on the basis of these two studies, it is reasonable to assume that the loss of xanthine oxidase activity, blocking the catabolism of hypoxanthine, would make more of this purine, and possibly its precursors, available for reutilization.

The incorporation of exogenously administered guanine by this subject was comparatively small. Although the excretion of $\mathrm{C}^{14}$-labeled purines in his urine (Figure 2, curve A) is similar to those observed by Sørensen after the administration of uric acid-2-C ${ }^{14}$ to normal individuals (27), the secóndary slow phase of excretion suggests delayed turnover after incorporation of a portion of the guanine. This was confirmed by the findings of labeled adenine and substituted guanines in his urine, the significance of which will be discussed.

The slow phase of excretion of the labeled urinary purines after the administration of hypoxanthine-8- $\mathrm{C}^{14}$ differed from that observed after adenine-8- $\mathrm{C}^{14}$ and guanine-8-C $\mathrm{C}^{14}$ (Figure 2). This difference indicates a greater turnover of labeled purines after the administration of hypoxanthine$8-\mathrm{C}^{14}$. The reason for this more rapid excretion rate is not known, but a hypothesis, currently being investigated, is that the proportionate distribution of purine nucleotides to their different pools may vary according to the source or method of synthesis of the nucleotide. It is possible that a greater proportion of adenylic acid (AMP) and guanylic acid (GMP) formed from IMP is distributed to more dynamic pools, whereas AMP and GMP synthesized from preformed bases or nucleosides are distributed, in greater proportion, to less dynamic pools.

Figure 9 is a schema of the intermediary metabolism of purines derived from a variety of biological systems. It illustrates the probable major pathways of purine interconversion in this subject and demonstrates the metabolic block that exists by presenting xanthine and hypoxanthine as the end products of purine metabolism.

The interconversion of the three administered purines is demonstrated by the appearance of the $\mathrm{C}^{14}$ label in all of the isolated urinary purines after each study. Labeling of all eight purines was found within the first 24 hours after adenine- $8-C^{14}$

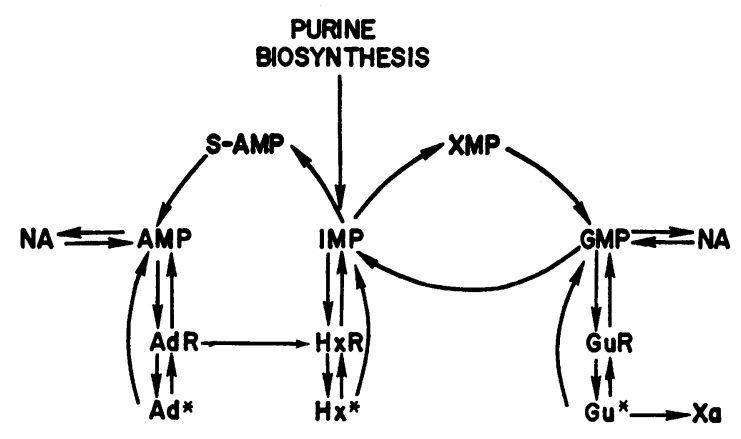

Fig. 9. Schematic diagram of probable metabolic INTERRELATIONSHIPS OF PURINE COMPOUNDS IN A XANTHINE OXIDASE-DEFICIENT SUBJECT. Purine bases administered in this study are shown by asterisks. Abbreviations: nucleic acids (NA), adenylosuccinic acid (S-AMP), inosine $(\mathrm{HxR})$, guanosine $(\mathrm{GuR})$, adenine (Ad), hypoxanthine $(\mathrm{Hx})$, guanine $(\mathrm{Gu})$, xanthine (Xa), adenylic acid (AMP), inosinic acid (IMP), xanythylic acid (XMP), guanylic acid (GMP), and adenosine (AdR).

and hypoxanthine- $8-C^{14}$ were given and within 48 hours after giving guanine-8-C $\mathrm{C}^{14}$. This time difference in appearance of labeling of the various urinary purines is probably only dose related as labeling was always found in at least one of the substituted guanines and adenine isolated from the first 4-hour urinary sample collected after each of the three studies.

The specific activity of the different urinary purines approached equality as they decayed with time in each study (Figures 3,6, and 7). This occurred most rapidly after the administration of hypoxanthine-8- $\mathrm{C}^{14}$ and with slower but comparatively equal rates after the administration of adenine-8- $\mathrm{C}^{14}$ and guanine-8-C $\mathrm{C}^{14}$ (Figures 4 and 5). The rapid conversion and even distribution of the hypoxanthine label, as shown by the equal specific activities of urinary adenine, guanine derivatives, hypoxanthine, and xanthine (Figure 7 ), reflect the central position of IMP in the synthesis of AMP and GMP as seen in Figure 9. Zimmerman and Magasanik have demonstrated the conversion and equal distribution of administered hypoxanthine-8- $\mathrm{C}^{14}$ and inosine-8- $\mathrm{C}^{14}$ to the adenine and guanine of bacterial nucleic acids (20). Studies with bacteria and mammalian cells have demonstrated that immediately after incorporation less than half of the exogenously introduced labeled adenine or guanine is converted to the other pu- 
rine base within the nucleic acids of the host cells $(20,22,23)$. Except for the excretion of the unincorporated purine seen in the initial samples, the early preferential labeling of the adenine or guanine derivatives in this subject's urine during the first two studies probably reflects this disproportionate initial distribution of the administered $\mathrm{pu}-$ rine base. However, with time, turnover, and reutilization, an increasing proportion of the original purine base is converted through IMP to the other, and equilibrium is eventually reached.

Although it can be assumed that the portion of the administered bases that have been retained and converted have been utilized, more definite evidence for utilization is present in the finding of labeled substituted guanines in the subject's urine after each of the three studies. Recent investigations have shown that 1-methylguanine, $N^{2}$-methylguanine, and 7-methylguanine are not formed by the methylation of guanine as a free base or mononucleotide but only after the incorporation of GMP into soluble RNA (28-30). The finding of these labeled substituted guanines in the first samples indicates that conversion of the purine, synthesis and degradation of soluble RNA, and excretion of the methylated purine occurred within a 4-hour period, an observation that tends to invalidate the concept that rapid labeling of urinary uric acid indicates a bypass of nucleic acid by the purine precursors (19). Additional evidence for utilization of hypoxanthine was obtained when labeled adenine and guanine were isolated from the acid soluble nucleotides of the erythrocytes and the nucleic acids of the leukocytes obtained from the subject during the third study.

The disproportionately larger amount of xanthine consistently excreted by this and other xanthinuric subjects draws attention to the origin of xanthine and hypoxanthine. In normal individuals the enzymatic oxidation of hypoxanthine and xanthine makes it impossible to quantitate the relative contribution of AMP and GMP to xanthine and uric acid. In a xanthinuric subject the only known pathways for the interconversion of hypoxanthine to xanthine must have IMP as an intermediary (Figure 9). It can be argued that xanthine oxidase may not be absent in a xanthinuric subject but deficient in its ability to oxidize xanthine while still being able to oxidize hypoxanthine. This seems unlikely in view of the demonstration of Engelman and his associates (3) that extracts of liver and jejunal mucosa from their xanthinuric subject failed to oxidize both hypoxanthine and xanthine as compared to their control studies. Our in vivo radioisotope studies confirm this; after the injection of adenine-8-C $\mathrm{C}^{14}$ we found the initial specific activity of hypoxanthine to be 27 times greater than that of xanthine, and it remained greater for over 17 days. In addition the initial specific activity of hypoxanthine was over ten times greater than that of xanthine after the injection of hypoxanthine-8- $\mathrm{C}^{14}$.

In this subject xanthine can originate from the catabolism of either xanthylic acid (XMP) or GMP as shown in Figure 9. The close similarities in the specific activities of xanthine, guanine, 7 -methylguanine, $N^{2}$-methylguanine, and 1-methylguanine noted, and their dissimilarity, early in the studies, to adenine and hypoxanthine, indicate that they all originate from a common precursor, probably GMP, although XMP cannot be excluded.

Hypoxanthine also has two possible pathways of production, one by the degradation of AMP to adenosine (AdR) and the other directly from IMP. Our data suggest that both of these mechanisms are operative. The moderately lower specific activity of hypoxanthine, as compared to adenine, during the first 17 days after the injection of adenine-8- $\mathrm{C}^{14}$ indicates a certain proportion of the excreted hypoxanthine was being diluted by a nonlabeled source, either by a large hypoxanthine pool or by the direct catabolism of newly synthesized and nonlabeled IMP (Figure 9). The specific activities of hypoxanthine and adenine were approximately equal after the first sample following the injection of hypoxanthine-8- $\mathrm{C}^{14}$. This indicates that both hypoxanthine and adenine were originating from the same pool of labeled IMP.

The greater retention and utilization of adenine as compared to guanine, the ease of interconvertibility of the purine bases, and the proportionately greater excretion of xanthine and other guanine derivatives shown by this subject are all compatible with the concepts expressed by McFall and Magasanik (22) that in mammalian cells the metabolism of purines favors the interconversion of purines to adenine nucleotides, the retention of the adenine nucleotides as a purine reservoir, and the degradation of guanine derivatives not converted or utilized. 


\section{Summary}

The utilization and excretion of purines by a xanthinuric subject have been studied using enzymatic, chromatographic, spectrophotometric, and radioisotopic methods.

The data confirm the replacement of uric acid by its precursor oxypurines, especially xanthine, without significant change in the nonoxypurines. They also demonstrate the incorporation of administered adenine, hypoxanthine, and guanine, in order of extent of incorporation, and the subsequent interconversion of the incorporated bases. The excretion of the labeled converted purines was studied and discussed relative to their possible relation to the intermediary metabolism and utilization of purines.

\section{Acknowledgments}

We are indebted to Miss Giannina Zatti and Miss Margaret Frintzilas for their excellent technical assistance.

\section{References}

1. Ayvazian, J. H. Xanthinuria and hemochromatosis. New Engl. J. Med. 1964, 270, 18.

2. Dent, C. E., and G. R. Philpot. Xanthinuria : an inborn error (or deviation) of metabolism. Lancet 1954, 1, 182.

3. Engelman, K., R. W. E. Watts, J. R. Klinenberg, A. Sjoerdsma, and J. E. Seegmiller. Clinical, physiological and biochemical studies of a patient with xanthinuria and pheochromocytoma. Amer. J. Med. 1964, 37, 839.

4. Prætorius, E., and H. Poulsen. Enzymatic determination of uric acid, with detailed directions. Scand. J. clin. Lab. Invest. 1953, 5, 273.

5. J $\phi$ rgensen, S., and H. E. Poulsen. Enzymic determination of hypoxanthine and xanthine in human plasma and urine. Acta pharmacol. (Kbh.) 1955, $11,223$.

6. Fister, H. J. Manual of Standardized Procedures for Spectrophotometric Chemistry. New York, Standard Scientific Supply Corp., 1950, p. 728.

7. Lalezari, P. A new technic for separation of human leukocytes. Blood 1962, 19, 109.

8. Schneider, W. C. Phosphorous compounds in animal tissues. I. Extraction and estimation of desoxypentose nucleic acid and of pentose nucleic acid. J. biol. Chem. 1945, 161, 293.

9. Mejbaum, W. Uber die Bestimmung kleiner Pentosemengen, insbesondere in Derivaten der Adenylsaüre. Hoppe-Seylers Z. physiol. Chem. 1939, 258, 117.
10. Burton, K. A study of conditions and mechanism of diphenylamine reaction for the colorimetric estimation of deoxyribonucleic acid. Biochem. J. $1956,62,315$.

11. Ayvazian, J. H., and L. F. Ayvazian. Changes in serum and urinary uric acid with the development of symptomatic gout. J. clin. Invest. 1963, 42, 1835.

12. Weissmann, B., P. A. Bromberg, and A. B. Gutman. The purine bases of human urine. I. Separation and identification. J. biol. Chem. 1957, 224, 407.

13. Weissmann, B., P. A. Bromberg, and A. B. Gutman. The purine bases of human urine. II. Semiquantitative estimation and isotope incorporation. J. biol. Chem. 1957, 224, 423.

14. Wyngaarden, J. B., A. E. Blair, and L. Hilley. On the mechanism of overproduction of uric acid in patients with primary gout. J. clin. Invest. 1958, 37, 579.

15. Jørgensen, S. Hypoxanthine and xanthine accumulated in stored human blood: determination of the relative amounts by spectrophotometry. Acta pharmacol. (Kbh.) 1955, 11, 265.

16. Bergmann, F., and S. Dikstein. Studies on uric acid and related compounds. III. Observations on the specificity of mammalian xanthine oxidases. J. biol. Chem. 1956, 223, 765.

17. Klenow, $H$. The enzymic oxidation and assay of adenine. Biochem. J. 1952, 50, 404.

18. Dickinson, C. J., and J. M. Smellie. Xanthinuria. Brit. med. J. 1959, 2, 1217.

19. Benedict, J. D., M. Roche, T. F. Yü, E. J. Bien, A. B. Gutman, and D. Stetten, Jr. Incorporation of glycine nitrogen into uric acid in normal and gouty man. Metabolism 1952, 1, 3.

20. Zimmerman, E. F., and B. Magasanik. Utilization and interconversion of purine bases and ribonucleosides by Salmonella typhimurium. J. biol. Chem. 1964, 239, 293.

21. Magasanik, B. In The Bacteria, I. C. Gunsalus and R. Y. Stanier, Eds. New York, Academic Press, 1962, vol. 3, p. 295.

22. McFall, E., and B. Magasanik. The control of purine biosynthesis in cultured mammalian cells. J. biol. Chem. 1960, 235, 2103.

23. Shapira, J., I. Bornstein, W. Wells, and R. J. Winzler. Metabolism of human leukocytes in vitro. IV. Incorporation and interconversion of adenine and guanine. Cancer Res. 1961, 21, 265.

24. Abrams, R., and J. M. Goldinger. Formation of nucleic acid purines from hypoxanthine and formate in bone marrow slices. Arch. Biochem. 1952, 35, 243.

25. Wyngaarden, J. B., J. E. Seegmiller, L. Laster, and A. E. Blair. Utilization of hypoxanthine, adenine and 4-amino-5-imidazole-carboxamide for uric acid synthesis in man. Metabolism 1959, 8, 455. 
26. Wheeler, G. P., and J. A. Alexander. Searches for exploitable biochemical differences between normal and cancer cells. VI. Metabolism of purines in vivo. Cancer Res. 1961, 21, 390.

27. Sørensen, L. B. The elimination of uric acid in man. Scand. J. clin. Lab. Invest. 1960, 12 (suppl. 54), 1.

28. Fleissner, E., and E. Borek. A new enzyme of RNA synthesis: RNA methylase. Proc. nat. Acad. Sci. (Wash.) 1962, 48, 1199.
29. Svensson, I., H. G. Boman, K. G. Eriksson, and K. Kjellin. Studies on microbial RNA. I. Transfer of methyl groups from methionine to soluble RNA from Escherichia coli. J. molec. Biol. 1963, 7, 254.

30. Hurwitz, J., M. Gold, and M. Anders. The enzymatic methylation of ribonucleic acid and deoxyribonucleic acid. III. Purification of soluble ribonucleic acid methylating enzymes. J. biol. Chem. 1964, 239, 3462. 